\title{
PENGEMBANGAN MULTIMEDIA PEMBELAJARAN EKONOMI MELALUI APLIKASI AUTOPLAY UNTUK SISWA KELAS X MA DARUL QUR'AN
}

\author{
Zinnurain ${ }^{1}$, Hadi Gunawan Sakti ${ }^{2}$ \\ ${ }^{1,2}$, Teknologi Pendidikan Universitas Pendidikan Mandalika Mataram \\ zinnurain@ikipmataram.ac.id, hadigunawansakti@ikipmataram.ac.id
}

\begin{abstract}
Abstrak. Penelitian ini bertujuan untuk menghasilkan Multimedia Pembelajaran Ekonomi Melalui Aplikasi Autoplay yang layak digunakan ditinjau dari segi isi, desain, dan media. Penelitian ini menggunakan metode Research and Development (R\&D). Subjek dalam penelitian ini adalah siswa kelas X MA Darul Quran Bengkel, Kediri, Lombok Barat. Ujicoba multimedia dilakukan oleh ahli materi, ahli desain, dan ahli media. Hasil penelitian ini adalah sebagai berikut. hasil penilaian dari ahli isi terhadap multimedia interaktif diperoleh 95,78\%, dengan kualifikasi sangat baik, sehingga secara umum tidak perlu direvisi.. Hasil penilaian dari seorang ahli desain pembelajaran sebesar $74 \%$ dengan kategori "Baik". Hasil penilaian dari ahli media sebesar 84,44\% dengan kategori " Baik". Hasil ujicoba kelompok kecil diperoleh 92,5\% dengan kategori "sangat baik". Ujicoba kelompok besar sebesar 93,19\% dengan kategori "sangatbaik". Hasil penilaian menunjukkan multimedia pembelajaran ini cocok digunakan dalam pembelajaran sehingga kayak untuk dipergunakan lebih lanjut lagi.
\end{abstract}

Kata Kunci : pengembangan, multimedia, ekonomi.

\section{PENDAHULUAN}

Kebutuhan akan sumber/bahan untuk belajar saat ini menjadi perhatian yang utama pada setiap satuan pendidikan. MA. Darul Al Qur'an Kabupaten lombok Barat adalah salah satu dari sekian bayak lembaga swasta pendidikan yang tergolong masih memiliki kendala dalam pelaksanaan kegiatan-kegiatan belajar mengajarnya. Kendala tersebut terlihat sekali, terutama pada pelaksanaan kegiatan pembelajaran di kelas X pada mata pelajaran Ilmu Pengetahuan Sosial adalah 6.5 nilai ratarata tersebut belum mencapai SKBM, yakni 7.5 sesuai dengan hasil observasi dengan kepala sekolah dan guru bidang studinya. Kendala lainya juga yakni rendahnya hasil belajar pada mata pelajaran ekonomi pada kelas $\mathrm{X}$ terjadi dikarenakan penggunaan metode pengajaran yang kurang variatif sehingga selalu bersifat menoton, disamping itu pebelajar juga mengalami kesulitan memahami dan menghafal materi yang di ajarkan oleh gurunya dengan kondisi tersebut suasana proses pembelajaran kurang menyenangkan. Secara Umumnya, media yang digunakan pada kegiatan pembelajaran di MA. Darul AlQur'an
Kabupaten Lombok Barat dikelas X sangatlah sederhana padahal sarana pendukung sudah memadai, seperti tersedianya lab. Komputer dan LCD Proyektor.

Multimedia interaktif merupakan suatu tampilan media yang dirancang oleh desainer agar tampilan memenuhi fungsi menginformasikan pesan dan memiliki interaktifitas kepada penggunanya. Mempertimbangkan hal-hal tersebut di atas, maka sangat perlu dilakukan pengembangan media pembelajaran dalam bentuk multimedia interaktif, sehingga dalam penelitian ini pengembang mengangkat judul: Pengembangan Multimedia Melalui Aplikasi Autoplay Pada Mata Pelajaran Ekonomi di kelas X di MA. Darul Qur"an, Kabupaten Lombok Barat.

\section{Tujuan Pengembangan}

Tujuan pengembangan adalah menghasilkan produk Bahan ajar melalui aplikasi Autoplay yang layak untuk digunakan dalam kegiatan pembelajaran mengajar.

\section{Kajian Pustaka}

Secara sederhana Mutimedia diartikan sebagai persentasi materi dengan menggunakan kata-kata dan gambar-gambar (Mayer, 2001:1). 
Secara lebih luas Multimedia diartikan sebagai pengintegrasian system komunkasi dalam sebuah perangkat khusus, seperti televisi, radio, komputer, notebook, netbook. (Darmawan, 2011:32). Dalam penggunaan aplikasi Autoplay sebagai pembuatan mulimedia ini dapat memberikan kemudahan dalam mendisain pembelajaran,agar didalam mendisain pembelajaran perlu diperhatikan pada pemilihan warna latar dengan warna teks, sehingga kombinasi tersebut menjadi lebih menarik tampilannya. Dengan demikian, pembelajaran menjdi lebih efektif dan menyenangkan. Autoplay merupakan perangkat lunak untuk membuat perangkat lunak multimedia dengan mengitegrasikan berbagai tipe media yang dikombinasikan. Misalnya: gambar, suara, video, teks, dan flash ke dalam program yang dibuat. Keberadaan mata pelajaran ekonomi merupakan sebagai suatu disiplin ilmu yang sangat diperlukan karena manusia selalu dihadapkan untuk membuat pilihan dalam kehidupannya. Oleh karena itu, dalam pembelajaran ilmu ekonomi harus memudahkan siswa untuk mampu membuat pilihan-pilihan secara rasional dan membuat siswa dapat menggunakan konsep-konsep dalam ilmu ekonomi untuk menganalisis persoalan-persoalan ekonomi personal dan kemasyarakatan. Metode pemecahan masalah yang digunakan dalam pembelajaran ekonomi diturunkan dari metode ilmiah, yang menekankan pada analisis atas dasar logika dapat diterapkan dalam pembelajaran ekonomi.

\section{METODE PENLITIAN}

Selanjutnya dalam penelitian dan pengembangan ini, model yang menjadi acuan adalah model procedural penelitian pengembangan yang dikembangkan oleh Brog \&Gall, 1983:775-776), yang meliputi langkahlangkah berikut; (1) Reseach and information collecting, (2) Planning, (3) Develop Preliminary form of product, (4) Preliminary filed testing, (5) Main product revision, (6) Main filed testing, (7) Operational product revision, (8) Operational filed testing, (9) Final product revision (10) Dessemination and
Implementation. Berdasarkan model pengembangan yang dikembangkan oleh Brog \& Gall, terdapat sepuluh langkah procedural yang harus dilakukan oleh pengembang. Akan tetapi dalam kegiatan penelitian ini pengembang hanya menggunakan 8 (delapan) langkah saja.

Adapun yang menjadi subjek coba dalam penelitian ini adalah; ahli isi atau materi, ahli media pembelajaran, ahli desain, guru bidang studi dan pebelajar Kelas X MA. Darul Qur'an. Berdasarkan data yang akan digunakan, data dibagi kedalam dua jenis, yaitu data kualitatif dan data kuantitatif. Data kualitatif didapatkan dari hasil wawancara dan hasil sasaran ahli isi, ahli desain, dan ahli media, baik pada tahap uji validasi atas uji lapangan. Sedangkan kuantitatif diperoleh dari hasil angket, yang disebarkan kepada subjek coba. Untuk memperoleh sejumlah data yang diharapkan, dalam penelitian ini digunakan instrument pengumpulan data yaitu wawancara dan angket. Sedangkan Analisis data dalam penelitian dan pengembangan ini dibagi dalam dua jenis, yaitu analisis deskriptif kualitatif dan analisis statistik deskriptif.

Setelah didapatkan hasil dari data yang diolah dengan menggunakan rumus diatas, hasil tersebut dicocokan dengan kriteria kelayakan, dapat dilihat pada tabel 3.1 sebagai berikut:

Tabel 3.1 Kriteria Tingkat Kelayakan

\begin{tabular}{|c|c|c|c|}
\hline Kategori & Presentase & Kualifikasi & Ekuivalen \\
\hline A & $76 \%-100 \%$ & Valid & Sangat Laya \\
B & $51 \%-75 \%$ & Cukup valid & Layak \\
C & $35 \%-50 \%$ & Kurang valid & Cukup \\
D & $0 \%-34 \%$ & Kurang Valid & Kurang Layak \\
\hline
\end{tabular}

Keterangan pada tabel 3.1 kriteria tingkat kelayakan yakni:

a) Apabila media yang diuji cobakan tersebut mencapai tingkat presentase $76 \%$ - 100\%, maka media tersebut tergolong kualifika Sangat valid/ layak.

b) Apabila media yang diuji cobakan tersebut mencapai tingkat presentase 51\% - 75\%, maka media tersebut tergolong kualifikasi valid/layak. 


\section{Hasil Pengembangan Ahli Materi}

Hasil penilaian ahli isi terhadap bahan ajar multimedia interaktif dapat dilihat dalam tabel 4.1 sebagai berikut:

Tabel 4.1 Data Hasil Penilaian Ahli Isi Materi Terhadap Multimedia Interaktif

\begin{tabular}{|c|c|c|c|}
\hline Jumlah item pertanyann & Skor & Frekuensi & Persentase \\
\hline 19 & 5 & 15 & $78,94 \%$ \\
\hline & 4 & 4 & $16,84 \%$ \\
\hline Jumlah & & & $95,79 \%$ \\
\hline
\end{tabular}

\section{Ahli Media}

Hasil penilaian ahli media pembelajaran terhadap bahan ajar multimedia interaktif pada tabel 4.2 adalah sebagai berikut :

Tabel 4.2 Hasil Penilaian Ahli Media Pembelajaran Terhadap Bahan Ajar multimedia Ineteraktif

\begin{tabular}{|c|c|c|c|}
\hline Jumlah item pertanyaan & Skor & Frekuensi & Persentase \\
\hline 9 & 5 & 2 & $22,22 \%$ \\
\hline & 4 & 7 & $62,22 \%$ \\
\hline Jumlah & & & $\$ 4,44 \%$ \\
\hline
\end{tabular}

\section{Ahli Desain}

Dibawah ini akan dipaparkan hasil penilaian Ahli Desain Pembelajaran terhadap produk pengembangan berupa bahan ajar multimedia interaktif.

Tabel 4.3 Hasil Penilaian Ahli Desain Pembelajaran Terhadap Produk Pengembangan Berupa Bahan Ajar Multimedia Interaktif

\begin{tabular}{|c|c|c|c|}
\hline Jumlah item pertanyaan & Skor & Frekuensi & Persentase \\
\hline \multirow{3}{*}{10} & 5 & 3 & $30 \%$ \\
\cline { 2 - 4 } & 4 & 4 & $32 \%$ \\
\hline & 3 & - & \\
\hline & 2 & 3 & $12 \%$ \\
\hline Jumlah & & & $\mathbf{7 4} \%$ \\
\hline
\end{tabular}

\section{Ujicoba Kelompok Kecil}

Berdasarkan penilaian/ tanggapan sebagaimana tercantum dalam tabel, diketahui bahwa rata-rata persentase tingkat pencapaian bahan ajar 92,5\%, rerata tersebut bila dikonversikan dengan tabel kelayakan, maka bahan ajar multimedia interaktif berada dalam kualifikasi sangat baik dan tidak perlu direvisi.
Rangkuman masukan, saran, dan komentar 12 orang siswa dalam uji coba kelompok kecil yang berkenaan dengan Bahan ajar adalah sebagai berikut :

Tabel 4.5 Revisi masukan, saran dan komentar Uji Coba Kelompok Kecil Pada Bahan Ajar

\begin{tabular}{|l|l|l|}
\hline No & Masukan,Saran, dan Komentar & \multicolumn{1}{|c|}{ Revisi } \\
\hline 1 & Bahan ajar mudah dipahami & Tidak ada revisi \\
\hline 2. & Sebaiknya tampilan lebih cerah & $\begin{array}{l}\text { Penambahan kecerahan wama } \\
\text { pada sampul }\end{array}$ \\
\hline 3 & Gambamya yang menarik & Tidak ada revisi \\
\hline
\end{tabular}

Ujicoba Kelompok Besar

Berdasarkan hasil uji coba kelompok besar sebagaimana tercantum pada tabel, skor yang diperoleh terhadap 10 komponen bahan ajar 30 siswa adalah skor 5 ( sangat baik), skor 4 (Baik), skor 3 (Cukup baik). Rerata persentase diperoleh sebesar 93,19 \% Setelah dikonversikan dengan tabel konversi diketahui bahwa bahan ajar multimedia interaktif berada dalam kualifikasi sangat baik. Rangkuman masukan, saran, dan komentar dari siswa berkenaan dengan bahan ajar adalah sebagai berikut :

Tabel 4.41 Revisi masukan, Saran Dan Komentar Terhadap Bahan ajar multimedia interaktif

\begin{tabular}{|l|l|l|}
\hline No & \multicolumn{1}{|c|}{$\begin{array}{c}\text { Masukan,saran dan } \\
\text { komentar }\end{array}$} & \multicolumn{1}{c|}{ Revisi } \\
\hline 1 & $\begin{array}{l}\text { Bahan ajar multimedia } \\
\text { mudah dipahami }\end{array}$ & $\begin{array}{l}\text { Tidak } \\
\text { direvisi }\end{array}$ \\
\hline 2 & $\begin{array}{l}\text { Ukuran tulisanya besar } \\
\text { hurufnya mudah dibaca }\end{array}$ & $\begin{array}{l}\text { Tidak } \\
\text { direvisi }\end{array}$ \\
\hline
\end{tabular}

\section{KESIMPULAN}

Pengembangan bahan ajar multimedia interaktif mata pelajaran ekonomi ini menggunakan model pengembangan borg dan gall yang proses pengembangannya hanya sampai pada tahap kesepuluh tahap pengembangan. Berdsarkan hasil penelitian tersebut, maka dapat disimpulkan bahwa dari beberapa uji ahli isi, media dan disain dan uji coba kelompok kecil dan kelompok besar 
bahwa pengembangan multimedia interaktif dapat kualifikasi Baik (Layak).

\section{SARAN}

Multimedia ini dapat dikembangkan untuk kelas dan semester yang laian dalam tingkat satuan pendidikan yang sama. Sedangkan untuk kelas dan semester yang sama paket ini perlu dilengkapi dengan program pengayaan dan remidiasi sebagaimana diamanatkan dalam standar proses KTSP.

Pengembangan produk ini disempurnakan, mengingat model yang digunakan adalah Borg dan Gall. Dalam setiap tahapan yang melakukan evaluasi perlu disesuaikan antara evaluasi yang dilakukan dengan penyajian materi. Multimedia akan lebih baik jika disertai dengan media cetak berupa buku ajar, buku panduan guru dan siswa.

\section{DAFTAR PUSTAKA}

AlanJanuszewski \& Michael Molenda, 2008. Educational Technology "A Definition with Commentary". Washington DC: AECT.

Ariani. Niken \& Dany Hariyanto, 2010. Pembelajaran Multimedia di Sekolah: Pedoman Pembelajaran Inspiratif, Konstruktif, dan Prospektif. Jakarta: Prestasi Pustaka.

Borg W,R. and Gall M. D., Educational Research : An Aintroduction, 4 th edition, London: Longman Inc., 2003.

BSNP, 2006. Badan Standar Nasional Pendidikan. Jakarta : Depdiknas.

Darmawan, Deni. 2011. Teknologi Pembelajaran Bandung: PT. Remaja Rosdakarya.

Dwiyogo, Waisis. 2008. Aplikasi Teknologi Pembelajaran: Media Pembelajaran Penjas dan Olahraga. FIP: Universitas Negeri Malang.

Hoftsteter, Fredt. 2001. Multimedia Literacy. New York: Mc. Grow-Hill Companies. Mayer, E Richard. 2009. Multimedia Learning: Prinsip-Prinsip dan Aplikasi. Yogyakarta: Pustaka Pelajar.
Mishra, Sanjaya. 2005. Interactive in Education and Training. Idea Grop Inc,

Rob PhillPA. 1997. The developer's Handbooks to Interactive Multimedia: A Paractive Guide for Educational Applications. London: Kogan Page Limited.

Seels, B.B. \& Richey, R.C. 1994. Intructional Technology: The Definition and Domain of the Field. Washington DC: AECT.

Seels, B.B. \& Richey, R.C. 1994. Ekologi Pembelajaran: Definisi dan Kawasannya (terjemahan). Washington DC: AECT.

Smaldino, Sharon E. 2005. Instuctional Technology and Multimedia For Learning. Eighth Edition. Columbus, Person Education. 